\title{
Crystallization-induced aggregation of block copolymer micelles: influence of crystallization kinetics on morphology
}

\author{
Adriana M. Mihut • Jérôme J. Crassous • \\ Holger Schmalz • Matthias Ballauff
}

\begin{abstract}
We present a systematic investigation of the crystallization and aggregation behavior of a poly $(1,2-$ butadiene)-block-poly(ethylene oxide) diblock copolymer (PB-b-PEO) in $n$-heptane. $n$-Heptane is a poor solvent for $\mathrm{PEO}$ and at $70^{\circ} \mathrm{C}$ the block copolymer self-assembles into spherical micelles composed of a liquid PEO core and a soluble PB corona. Time- and temperature-dependent light scattering experiments revealed that when crystallization of the PEO cores is induced by cooling, the crystal morphology depends on the crystallization temperature $\left(\mathrm{T}_{c}\right)$ : Below $30^{\circ} \mathrm{C}$, the high nucleation rate of the PEO core dictates the growth of the crystals by a fast aggregation of the
\end{abstract}

A. M. Mihut

Physical Chemistry I, University Bayreuth,

95440 Bayreuth, Germany

J. J. Crassous

Adolphe Merkle Institute, University Fribourg,

1723 Marly, Switzerland

H. Schmalz $(\bowtie)$

Macromolecular Chemistry II, University Bayreuth,

95440 Bayreuth, Germany

e-mail: holger.schmalz@uni-bayreuth.de

M. Ballauff

Soft Matter and Functional Materials,

Helmholtz-Zentrum Berlin fr Materialien und Energie

GmbH, Glienicker Strasse 100, 14109 Berlin, Germany

M. Ballauff (凶)

Department of Physics, Humboldt University Berlin,

Newtonstr. 15, 12489 Berlin, Germany micelles into meander-like (branched) structures due to a depletion of the micelles at the growth front. Above $30^{\circ} \mathrm{C}$ the nucleation rate is diminished and a relatively small crystal growth rate leads to the formation of twisted lamellae as imaged by scanning force microscopy. All data demonstrate that the formation mechanism of the crystals through micellar aggregation is dictated by two competitive effects, namely, by the nucleation and growth of the PEO core.

Keywords Block copolymer • Crystalline micelles • Self- assembly $\cdot$ Selective solvent

\section{Introduction}

Self-assembly of crystalline-coil block copolymers in solution has attracted steadily increasing attention during the last years since the resulting morphology may be largely influenced by the crystallizable block. In selective solvents, the insoluble block undergoes chain folding upon crystallization. Thus, the resulting morphology can be viewed as the solvent-soluble corona blocks being grafted on both sides of the lamellar crystalline core [1-3]. The chain-folded crystalline region leads to a dense packing of the amorphous blocks and results in highly stretched tethered chains. The overall shape thus depends on the interplay between the interfacial energy of the crystalline block and the solvent, and the stretching within the amorphous block [4]. Thus, the micellar architecture is strongly influenced by the crystallization conditions, such as temperature [9], and composition of the block copolymers [3, 5- 
By changing composition, solvent, and structure of the crystalline block, spherical [7, 11-13], cylindrical $[10,14,28]$, and lamellar micelles have been obtained [1, 3, 5, 15, 29]. Recently, Winnik et al. reported the possibility to obtain cylindrical micelles with controlled dimensions and architectures of organometallic block copolymers containing the crystallizable polyferrocenyldimethylsilane as one block. These authors, reported the transition from spherical micelles to wormlike, cylindrical or tubular morphologies in nonpolar selective solvent [8,16-18]. Recently, the formation of wormlike micelles was observed in which the corona had undergone a microphase separation in organic media due to crystallization-induced aggregation of triblock terpolymers [14].

In our previous studies, we demonstrated that solutions of poly(butadiene)-block-poly(ethylene oxide) in $n$-heptane present a good model system for the study of the interplay between crystallization and aggregation. For a symmetric PB- $b$-PEO block copolymer $\left(\mathrm{B}_{52} \mathrm{EO}_{48}^{5.6}\right)$ in $n$-heptane, a fast quenching into liquid nitrogen results in the formation of crystalline micelles retaining the spherical shape present in the molten state at $70^{\circ} \mathrm{C}$ [19]. If crystallization took place at $30^{\circ} \mathrm{C}$, a meander-like structure was formed. Moreover, in the case of a highly asymmetric PB- $b$-PEO block copolymer $\left(\mathrm{B}_{88} \mathrm{EO}_{12}^{29.5}\right)$ we observed rod-like micelles [20]. With time these rod-like micelles aggregate and re-crystallize in solution forming long needles. Investigation on a poly( $\epsilon$-caprolactone)- $b$-poly(ethylene oxide) (PCL- $b$-PEO) block copolymer showed that the morphology can be influenced by the crystallization temperature, due to an increased chain folding at lower crystallization temperatures [9].

All previous studies have highlighted the importance of the kinetics of crystallization for the resulting morphology. However, a more detailed investigation of the various factors influencing the micellization of semicrystalline systems is till missing. In this study, we discuss the effect of crystallization kinetics on the morphology formed upon crystallization- induced aggregation of spherical micelles of a symmetric poly(1,2-butadiene)-block-poly(ethylene oxide) diblock copolymer $\left(\mathrm{B}_{52} \mathrm{EO}_{48}^{5.6}\right)$. The evolution of the size of the aggregates and the kinetics at different crystallization temperatures $\left(T_{c}\right)$ was monitored by static (SLS) and dynamic light scattering (DLS). The resulting crystalline micellar morphologies were imaged by scanning force microscopy (SFM). The combination of the various techniques indicated that the final morphology is directly controlled by $T_{c}$ : meander-like structures formed at low $T_{c}$, whereas higher $T_{c}$ lead to the formation of twisted lamellae.

\section{Experimental section}

The poly(1,2-butadiene)-block-poly(ethylene oxide) diblock copolymer was synthesized via sequential anionic polymerization with a composition given by $\mathrm{B}_{52} \mathrm{EO}_{48}^{5.6}$ as described elsewhere [22-24]. The subscripts denote the mass fraction in percent and the superscript gives the overall number average molecular weight of the block copolymer in $\mathrm{kg} / \mathrm{mol}$. The molecular weights of the PB and PEO blocks are 2.9 and $2.7 \mathrm{~kg} / \mathrm{mol}$, respectively. The polydispersity index of the diblock copolymer is 1.02 . The samples were prepared from 0.1 wt. $\% n$-heptane solutions at different crystallization temperatures for the PEO block.

Differential scanning calorimetry (DSC) measurements on n-heptane solutions of $\mathrm{B}_{52} \mathrm{EO}_{48}^{5.6}$ (10 wt.\%) were performed using a Setaram MicroDSC III in screwcapped stainless aluminum cells. The samples were heated from 25 to $80^{\circ} \mathrm{C}$ and cooled again to $25^{\circ} \mathrm{C}$ at a scanning rate of $0.5^{\circ} \mathrm{C} \mathrm{min}{ }^{-1}$. This cycle was performed three times to check reversibility of the transitions. The samples were kept at $25^{\circ} \mathrm{C}$ for 60 and $20 \mathrm{~min}$ at $80^{\circ} \mathrm{C}$.

DLS and SLS were carried out on a ALV compact goniometer system equipped with a He-Ne laser $(\lambda=632.8 \mathrm{~nm})$. All measurements were performed on $0.1 \mathrm{wt} . \%$ solutions of $\mathrm{B}_{52} \mathrm{EO}_{48}^{5.6}$ in $n$-heptane at a scattering angle of $90^{\circ}$. The hydrodynamic radius $R_{H}$ derived from the second cumulant analysis was monitored in two degrees steps with a waiting time of $5 \mathrm{~min}$ at each temperature. The samples for the aggregation kinetics were first kept at $70^{\circ} \mathrm{C}$ during $20 \mathrm{~min}$ to erase the thermal history. Then, the samples were quenched in the DLS to different crystallization temperatures. $\mathrm{R}_{H}$ and $\mathrm{I} / \mathrm{I}_{0}$ were monitored every $15 \mathrm{~s}$ during $2 \mathrm{~h}$.

The SFM experiments were performed using a Dimension 3,100 M microscope (Veeco Instruments) equipped with a Nanoscope software operated in TappingMode at room temperature. The samples were prepared by spin-coating the 0.1 wt. $\% \mathrm{~B}_{52} \mathrm{EO}_{48}^{5.6}$ solution onto freshly cleaned silicon wafers. Scan rates between $0.5-1.0 \mathrm{~Hz}$ were used. The crystalline PEO block is much stiffer then the amorphous PB block which allowed us an imaging mode base on a mechanical contrast, complementary to the topographic imaging mode. 


\section{Results and discussion}

Influence of crystallization temperature $\left(T_{c}\right)$ on the micellar morphology

Recently, we described that crystallization of a poly(1, 2-butadiene)-block-poly(ethylene oxide) diblock copolymer $\left(\mathrm{B}_{52} \mathrm{EO}_{48}^{5.6}\right)$ in $n$-heptane yielded spherical and meander-like micelles via a fast quenching of the hot solutions $\left(70^{\circ} \mathrm{C}\right)$ to $30^{\circ} \mathrm{C}$ (pathway $\mathrm{A}$ ), and into liquid nitrogen (pathway B), respectively [19]. The micelles were composed of a crystalline PEO core and a soluble PB corona. The meander structure formed via crystallization-induced aggregation of spherical micelles upon cooling in $n$-heptane. In this study, samples with different thermal histories were prepared in order to investigate the influence of the crystallization conditions on the finally formed morphology. The $0.1 \mathrm{wt} . \%$ solutions of $\mathrm{B}_{52} \mathrm{EO}_{48}^{5.6}$ block copolymer in $n$-heptane were kept at $70^{\circ} \mathrm{C}$ for $20 \mathrm{~min}$ in order to erase any thermal history. Then they were quenched for two hours to 20,30 and $34^{\circ} \mathrm{C}$, respectively. The phase-contrast images clearly confirm the morphological difference between the crystals formed at a distinct $T_{c}$ (Fig. 1).

Figure 1a-d shows the meander-like morphologies formed in the solutions crystallized at 20 and $30^{\circ} \mathrm{C}$, respectively. The width of the meanders was found to be rather uniform, $35 \pm 5 \mathrm{~nm}$ (Fig. 1a,b) and $40 \pm$ $4 \mathrm{~nm}$ (Fig. 1c,d), quantified by measurements from over 50 crystals. The length distribution of the branches is relatively broad, ranging from 35 to $300 \mathrm{~nm}$ at $T_{c}=$ $30^{\circ} \mathrm{C}$. The branch lengths of the meanders formed at $20^{\circ} \mathrm{C}$, is much shorter, varying from 35 to $150 \mathrm{~nm}$.

At $30^{\circ} \mathrm{C}$ the width of the ribbon-like PEO core has an average value of $20 \pm 2 \mathrm{~nm}$, surrounded by an amorphous PB layer of $20 \pm 4 \mathrm{~nm}$. The bright areas correspond to the PEO block surrounded by the PB layer as the darker areas indicated in Fig. 1c. The higher contrast of the PEO core is related to a more dense packing of chains in a crystallite compared with the amorphous state. Similar values for the meanders were found in our previous work at this crystallization temperature. The overall thickness measured by SFM from the height images was 16 and $17 \mathrm{~nm}$ at 20 and $30^{\circ} \mathrm{C}$, respectively. The overall shape of the morphologies resembles that of a fractal growth [25], and is consistent with our previous investigations [19].

In contrast, when the solution is quenched to $34^{\circ} \mathrm{C}$ (Fig. 1e,f) a change of the crystal morphology is observed which hints to a twisted lamellae. The thickness of the twisted lamellae is $18 \mathrm{~nm}$, which is comparable
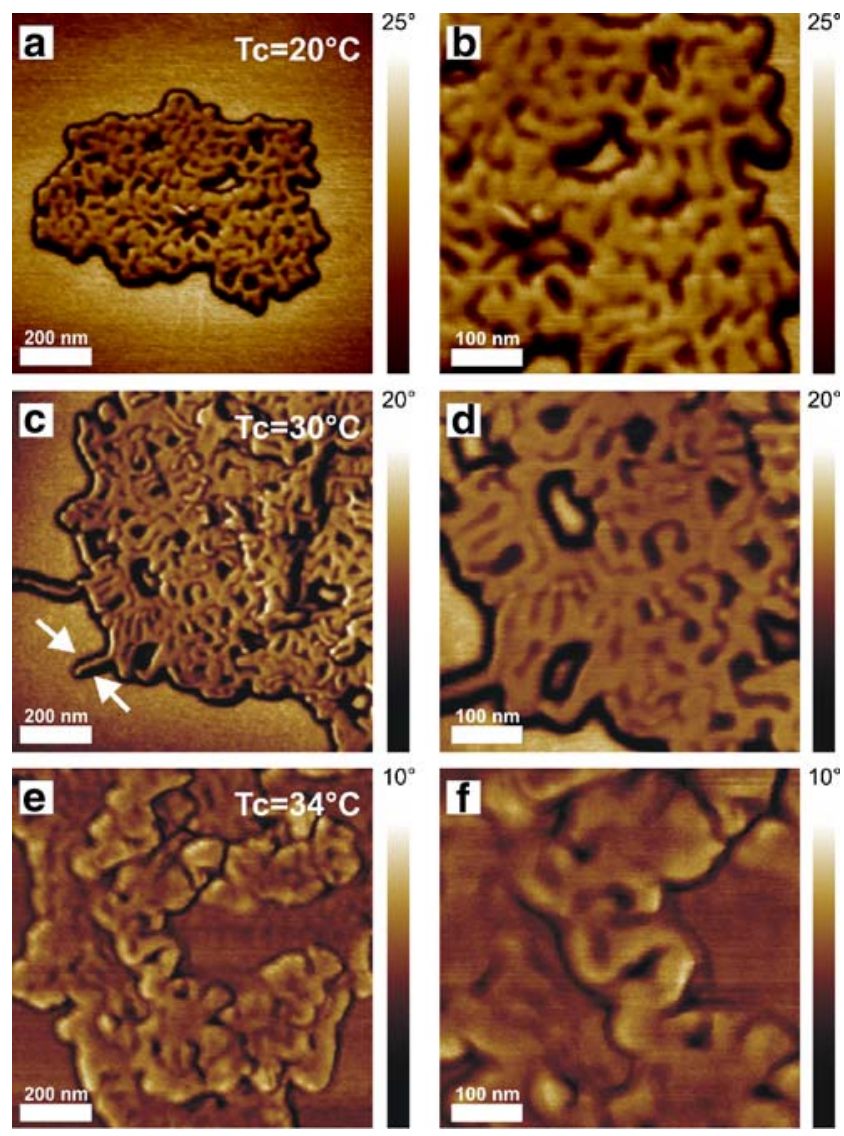

Fig. 1 SFM phase image of $\mathrm{B}_{52} \mathrm{EO}_{48}^{5.6}$ crystalline micelles from a 0.1 wt. $\%$ solution in $n$-heptane after quenching to $20^{\circ} \mathrm{C}(\mathbf{a}, \mathbf{b})$, $30^{\circ} \mathrm{C}(\mathbf{c}, \mathbf{d})$ and $34^{\circ} \mathrm{C}(\mathbf{e}, \mathbf{f})$. The arrows point out to the $\mathrm{PEO}$ block (light areas) and the surrounding PB layer (darker area) as can be visualized from the phase contrast difference between the two polymers

with that of the meanders. This shows that there is not change in chain folding due to different quenching temperatures $T_{c}$. The average width of the crystals increased to $80 \pm 18 \mathrm{~nm}$ (quantified from measurements of over 50 crystals) which is twice the size of the crystals formed at lower crystallization temperatures, however the widths are not as uniform as compared to that of the meanders formed at 20 or $30^{\circ} \mathrm{C}$.

In thin films, it has been demonstrated that the lamellae thickness increases with crystallization temperature [26, 27]. Large undercooling induced a large chain-folding number, whereas at higher $T_{c}$ the crystalline polymer chains adopted a fully extended conformation. In addition, investigations on a poly $(\epsilon-$ caprolactone)- $b$-poly(ethylene oxide) (PCL- $b$-PEO) block copolymer showed that the extend of chain folding, and as a result the final morphology, can 


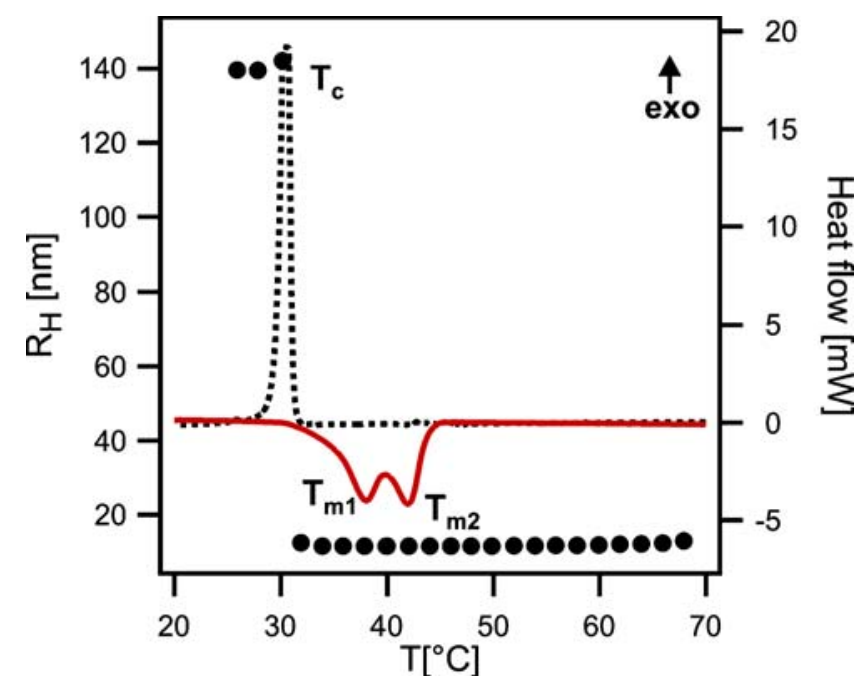

Fig. 2 Left: temperature dependence of the hydrodynamic radius (black circles) of a 0.1 wt.\% solution of $\mathrm{B}_{52} \mathrm{EO}_{48}^{5.6}$ upon cooling from 70 to $20^{\circ} \mathrm{C}$. Right: DSC cooling (black dash line) and heating scans (red line) of a $10 \mathrm{wt} . \%$ solution of $\mathrm{B}_{52} \mathrm{EO}_{48}^{5.6}$ in $n$-heptane

be influenced by the crystallization temperatures [9]. However, in our case the different morphology formed at $34^{\circ} \mathrm{C}$ does not result from a change in the extend of chain folding, as the thickness of the crystals is comparable to that formed at lower crystallization temperatures. This point will be discussed in more detail in the next section.

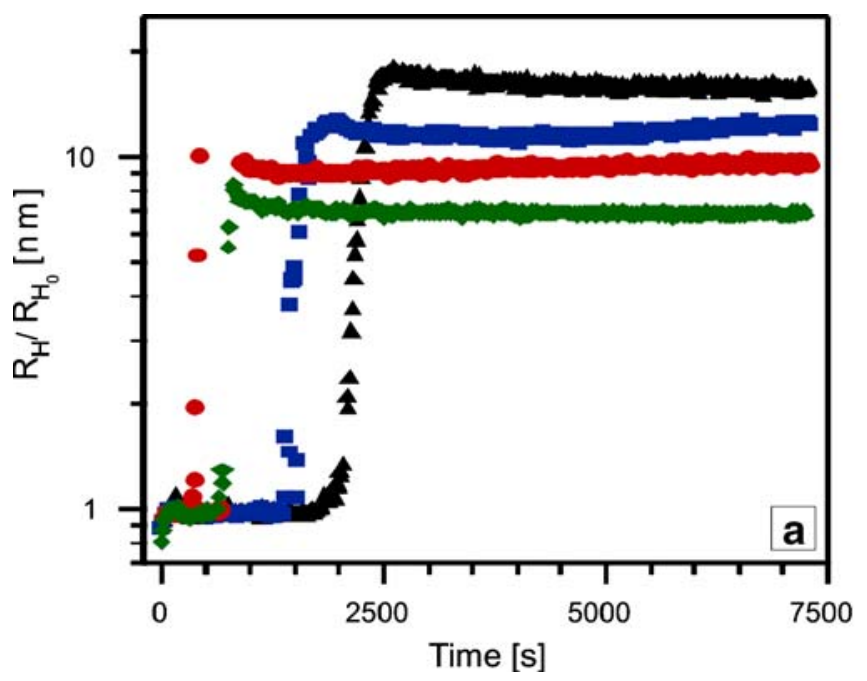

Fig. 3 Evolution of the normalized hydrodynamic radius $R_{H} / R_{H_{0}}$ (a) and of the normalized scattering intensity $I / I_{0}(\mathbf{b})$ of 0.1 wt. \% solution of $\mathrm{B}_{52} \mathrm{EO}_{48}^{5.6}$ in $n$-heptane first equilibrated
Kinetics and mechanism of structure formation

The structure formation upon cooling from 70 to $20^{\circ} \mathrm{C}$ of the $\mathrm{B}_{52} \mathrm{EO}_{48}^{5.6} n$-heptane solution has been investigated by DSC and DLS. DSC measurements (Fig. 2 Right) revealed a broaden crystallization transition between 27 and $32^{\circ} \mathrm{C}$ with a maximum crystallization peak at $30^{\circ} \mathrm{C}$. The onset of the crystallization at $30^{\circ} \mathrm{C}$ was supported by DLS measurements, in which an increase from 12 to $140 \mathrm{~nm}$ of the hydrodynamic radius $R_{H}$ was observed. This is consistent with our previous investigations (Fig. 2 Left) [19]. DSC shows a novel behavior in $n$-heptane solution, which indicated two melting endothermal peaks at $38^{\circ} \mathrm{C}\left(T_{m_{1}}\right)$ and $42^{\circ} \mathrm{C}\left(T_{m_{2}}\right)$, whereas in the bulk only a single melting peak at $47^{\circ} \mathrm{C}$ was observed. Since the double melting endotherms could not be observed in bulk, it is reasonably to conclude that this behavior is induced by the morphology formed in the solution. As the meanders are branched lamellar structures, the first melting endothermal peak from $38^{\circ} \mathrm{C}$ has to be related with the melting of the less perfect branched points, whereas the second melting peak from $42^{\circ} \mathrm{C}$ points out to the complete melting of the lamellar units. The DSC heating trace at $70^{\circ} \mathrm{C}$ is far away from the melting temperature of the crystals, i.e., no thermal history is expected at this temperature.

The kinetics of the crystallization/aggregation process and the size evolution of the aggregates were monitored by measuring the time dependence of the $\mathrm{R}_{H}$ and $I / I_{0}$ after fast quenching of the $0.1 \mathrm{wt} \%$

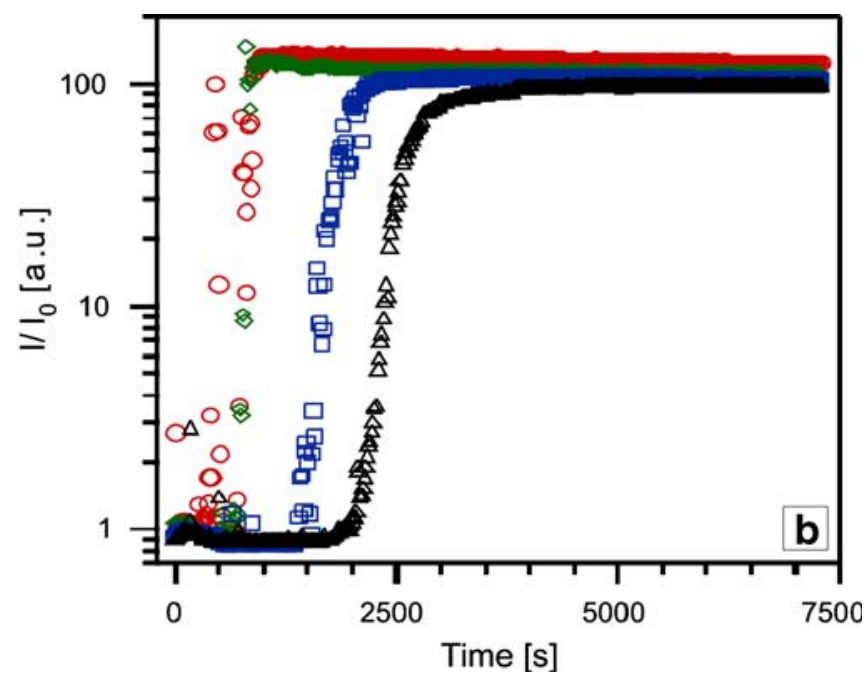

(blue square), $30^{\circ} \mathrm{C}$ (red circles) and $20^{\circ} \mathrm{C}$ (green diamond). The full symbols correspond to the $R_{H} / R_{H_{0}}$ and the empty symbols to $I / I_{0}$ 


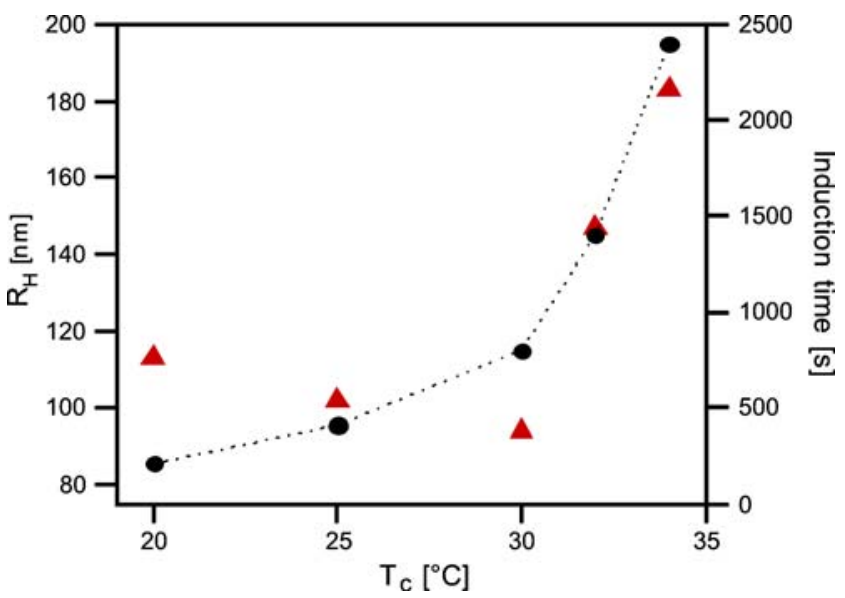

Fig. 4 Dependence of the size of crystalline micelles (black circles with dash line) and of the induction time of the primary nucleation process (red triangle) on the crystallization temperature $\left(T_{c}\right)$.

solution from $70^{\circ} \mathrm{C}$ to different $T_{c}$ directly in the DLS bath. Figure 3 displays the evolution with time of $R_{H} / R_{H_{0}}$ and $I / I_{0}$ while quenching to different $T_{c}$. The $\mathrm{R}_{H}$ and $\mathrm{I}$ at time $t$ was normalized to its initial average value $\mathrm{R}_{H_{0}}$ and $I_{0}$, respectively before the onset of the crystallization/ aggregation. The $\mathrm{R}_{H}$ retained a constant value of $12 \mathrm{~nm}$ when the solution is quenched to $35^{\circ} \mathrm{C}$ or higher temperatures. At temperatures below $35^{\circ} \mathrm{C}$ crystallization takes place in the micellar PEO core as monitored by the increase of $\mathrm{R}_{H}$ (Fig. 3a). This indicates rearrangement of micelles and growth into larger structures. An enhancement of the normalized intensity of about two decades marked this transition (Fig. 3b). $\mathbf{R}_{H}$ strongly depends on $T_{c}$, i.e., $\mathbf{R}_{H}$ decreases with decreasing $T_{c}$, from $195 \mathrm{~nm}$ at $T_{c}=34^{\circ} \mathrm{C}$ to $85 \mathrm{~nm}$ at $T_{c}=20^{\circ} \mathrm{C}$, respectively (Fig. 4).

A small induction time of the crystallization process was recorded at $T_{c} \leq 30^{\circ} \mathrm{C}$ (only few seconds), whereas at $T_{c}=34^{\circ} \mathrm{C}$ was delayed with $30 \mathrm{~min}$ (Fig. 4). The shortest induction time (400 s) was observed at $30^{\circ} \mathrm{C}$, where the maximum of the crystallization exotherm was observed in micro-DSC measurements (Fig. 2). Moreover, the crystallization temperature affects the aggregation time of the micelles, that is, the time until a stable $\mathrm{R}_{H}$ plateau is reached, after the onset of crystallization. The lowest aggregation time was observed at $T_{c} \leq 30^{\circ} \mathrm{C}$, as 225 and $470 \mathrm{~s}$ at 20 and $30^{\circ} \mathrm{C}$, respectively. At $T_{c}>30^{\circ} \mathrm{C}$, the aggregation time increased to $730 \mathrm{~s}$ at $34^{\circ} \mathrm{C}$.

The above results suggest the presence of two types of mechanisms in which the crystal growth proceeds in different manners. At $T_{c} \leq 30^{\circ} \mathrm{C}$, crystallization induced a high nucleation rate in the solution on a narrow micellar neighbors and fast advancing of the crystallization front in the solution leads to fast depletion of micelles at the growing front. Herein, the crystallization front, therefore the nucleation and growth process, propagates very fast in the solution.

At $T_{c}>30^{\circ} \mathrm{C}$, the nucleation rate is lowered and only few nuclei formed at the same time scale in solution. At $34^{\circ} \mathrm{C}$, the long induction time of crystallization hinders the detection of an endothermic signal in the DSC, that is, nucleation is too slow at this temperature in order to create nuclei at a slow cooling rate of $0.5^{\circ} \mathrm{C} \mathrm{min}-1$ (see Fig. 2). Due to the reduced number of nuclei/time the growth process is slow and no depletion of micelles occurred at the crystal growth front, as a gradual development of $\mathrm{R}_{H}$ to a stable value was observed (Fig. 3a). Here, the growth process has obviously becomes the step that determines the crystal pattern rather than the nucleation process. It is interesting to note that the crystal morphology is changed concomitantly from meanders (branched lamellae) to twist lamellae at $T_{c}>$ $30^{\circ} \mathrm{C}$ (Fig. 1).

\section{Conclusion}

We can hence conclude that the resulting morphology is controlled by two competitive effects, namely, by the nucleation and growth of the PEO micellar core: At lower $T_{c}$, the nucleation rate is high, the crystal growth front is accelerated which results in a meanderlike morphology. At higher $T_{c}$ the nucleation rate is lowered. Thus, the micelles have enough time to reach the growth front of the crystals favoring the formation of twisted lamellae. This procedure allows us to tune morphological structures in dependence on crystallization temperature by change of the growth kinetics.

Acknowledgements Financial support by the Deutsche Forschungsgemeinsschaft, SFB 840, Bayreuth, is gratefully acknowledged. We thank Dieter Gräbner (University of Bayreuth, BZKG) for conducting the DSC measurements. A.M.M. acknowledge the financial support from the European Community's "Marie-Curie Actions" under Contract No. MRTN-CT2004-504052 [POLYFILM].

\section{References}

1. Lotz B, Kovacs AJ (1966) Kolloid-Z Z Polym 209:97-114

2. Lotz B, Kovacs AJ, Bassett GA, Keller A (1966) Kolloid-Z Z Polym 209:115-128

3. Lin EK, Gast AP (1996) Macromolecules 29:4432-4441 
5. Richter D, Schneiders D, Monkenbusch M, Willner L, Fetters LJ, Huang JS, Lin M, Mortensen K, Farago B (1997) Macromolecules 30:1053-1068

6. Massey JA, Temple K, Cao L, Rharbi Y, Raez J, Winnik MA, Manners IJ (2000) Am Chem Soc 122:11577-11584

7. Xu JT, Fairclough JPA, Mai SM, Ryan AJJ (2003) Mater Chem 13:2740-2748

8. Shen L, Wang H, Guerin G, Wu C, Manners I, Winnik M (2008) Macromolecules 41:4380-4389

9. Du Z-X, Xu J-T, Fan Z-Q (2008) Macromol Rapid Commun 29:467-471

10. Du Z-X, Xu J-T, Fan Z-Q (2007) Macromolecules 40:76337637

11. Fu J, Luan B, Yu X, Cong Y, Li J, Pan C, Han Y, Yang Y, Li B (2004) Macromolecules 37:976-986

12. Xu JT, Jin W, Liang GD, Fan ZQ (2005) Polymer 46:1709_ 1716

13. Cao L, Manners I, Winnik MA (2002) Macromolecules 35:8258-8260

14. Schmalz H, Schmelz J, Drechsler M, Yuan J, Walther A, Schweimer K, Mihut AM (2008) Macromolecules 41:32353242

15. Zheng JX, Xiong HM, Chen WY, Lee KM, Van Horn RM, Quirk RP, Lotz B, Thomas EL, Shi AC, Cheng SZD (2006) Macromolecules 39:641-650

16. Guerin G, Raez J, Manners I, Winnik MA (2005) Macromolecules 38:7819-7827
17. Raez J, Barjovanu R, Massey JA, Winnik MA, Manners I (2000) Angew Chem Int Ed 39:3862-3865

18. Raez J, Tomba JP, Manners I, Winnik MAJ (2003) Am Chem Soc 125:9546-9547

19. Mihut AM, Chiche A, Drechsler M, Schmalz H, Cola ED, Krausch G, Ballauff M (2009) Soft Matter 5:208-213

20. Mihut AM, Drechsler M, Möller M, Ballauff M (2009) Macromol Rapid Commun. doi:10.1002/marc.200900571

21. Xu J-T, Fairclough JPA, Mai S-M, Ryan AJJ (2003) Mater Chem 13:2740-2748

22. Schmalz H, Lanzendörfer MG, Abetz V, Müller AHE (2003) Macromol Chem Phys 204:1056-1071

23. Schmalz H, Knoll A, Müller AJ, Abetz V (2002) Macromolecules 35:10004-10013

24. Castillo RV, Arnal ML, Müller AJ, Hamley IW, Castelletto V, Schmalz H, Abetz V (2004) Macromolecules 41:879-889

25. Reiter G, Hörner P, Hurtrez G, Riess G, Sommer JU, Joanny JFJ (1998) Surf Sci Technol 14:93-103

26. Sommer J-U, Reiter GJ (2000) Chem Phys 112:4384-4393

27. Reiter G, Sommer J-U (2000) J Chem Phys 112:4376-4383

28. Lazzari M, Scalarone D, Vazquez-Vazquez C, LopezQuintela MA (2008) Macromol Rapid Commun 29:352-357

29. Gädt T, Ieong NS, Cambridge G, Winnik MA, Manners I (2009) Nat Mater 8:144-150

30. Arlie J, Spegt P, Skoulios A (1967) Makromol Chem 104: 212-229

31. Kovacs A, Straupe C (1980) J Cryst Growth 48:210-226 